\title{
Studies on the Chemical Behavior of 3-(Nitroacetyl)-1-ethyl-4-hydroxyquinolin-2(1H)-one towards some Electrophilic and Nucleophilic Reagents
}

\author{
Magdy A. Ibrahim, * Hany M. Hassanin, Yassin A. Gabr and Youssef A. Alnamer \\ Department of Chemistry, Faculty of Education, Ain Shams University, Roxy 11711, Cairo, Egypt
}

\begin{abstract}
Uma variedade de sistemas heterocíclicos contendo o sistema 1-etilquinolin-2(1H)-ona, foi preparada a partir da reação de 3-(nitroacetil)-1-etil-4-hidroxiquinolin-2(1H)-ona com alguns reagentes eletrofílicos e nucleofílicos. Além da sua ciclização para 5-etil-2-(hidroxiimino)-2,3,4,5tetrahydrofuro[3,2-c] quinolina-3,4-diona, o composto 3-(nitroacetil)-1-etil-4-hidroxiquinolina2(1H)-ona foi bromado, clorado, formilado, acetilado, e condensado com cromona-3-carbonitrila e 2-amino-3-formilcromona. Alguns novos pirazolo[4,3-c]quinolina,pirimido [5,4-c]quinolina e derivados de quinolino[4,3- $b][1,5]$ benzodiazepina foram também sintetizados.
\end{abstract}

A variety of heterocyclic systems linked to 1-ethylquinolin-2(1H)-one was prepared from reaction of 3-(nitroacetyl)-1-ethyl-4-hydroxyquinolin-2(1H)-one with some electrophilic and nucleophilic reagents. Besides its cyclization to 5-ethyl-2-(hydroxyimino)-2,3,4,5tetrahydrofuro[3,2-c]quinoline-3,4-dione, the 3-(nitroacetyl)-1-ethyl-4-hydroxyquinolin-2(1H)one has been brominated, chlorinated, formylated, acetylated, and condensed with chromone-3carbonitrile and 2-amino-3-formylchromone. Some new pyrazolo[4,3-c]quinoline, pyrimido[5,4-c] quinoline and quinolino[4,3-b][1,5]benzodiazepine derivatives were also synthesized.

Keywords: $\beta$-ketoacid, 3-nitroacetylquinolinone, pyrazolo[4,3-c]quinolinones, pyrimido[5,4-c] quinolinones, cyclocondensation

\section{Introduction}

4-Hydroxyquinolin-2(1H)-ones and their derivatives represent a class of heterocyclic compounds that have been associated with several biological activities. ${ }^{1-6}$ The biological importance of quinolinones stimulated an intensive research work for the synthesis of many members of this class of compounds. ${ }^{7-10}$ In continuation of our previous reports on the synthesis of novel 4-hydroxyquinolin-2(1H)-ones starting from 3-(1-ethy 1-4-hydroxy-2-oxo-1,2-dihydroquinolin3-yl)-3-oxopropanoic acid (1), ${ }^{11}$ the present work aims to synthesize the 3-(nitroacetyl)-1-ethyl-4-hydroxyquinolin$2(1 H)$-one (4) and to study its reactivity towards a variety of chemical reagents.

\section{Results and Discussion}

In continuation to our work on the novel $\beta$-ketoacid $\mathbf{1},{ }^{11}$ we found that nitration of $\beta$-ketoacid $\mathbf{3}$ using a mixture of concentrated nitric acid and sulfuric acid gave the cyclized

\footnotetext{
*e-mail: magdy_ahmed1977@yahoo.com
}

product, 6-ethyl-4-hydroxy-3-nitropyrano[3,2-c]quinoline2,5(6H)-dione (3) via the non isolable intermediate 2 (Scheme 1). ${ }^{12}$ The reaction proceeds via nitration at the active methylene carbon with concomitant cyclization under the strongly acidic reaction conditions. The mass spectrum of compound 3 reveal the molecular ion peak at $\mathrm{m} / \mathrm{z} 302$ which is coincident with the formula weight (302.25) and supports the identity of the structure.

Basic hydrolysis of 3-nitropyrano[3,2-c] quinoline derivative 3 using $2 \mathrm{~mol} \mathrm{~L}^{-1}$ aqueous $\mathrm{NaOH}$ solution yielded the 3-(nitroacetyl)-1-ethyl-4-hydroxyquinolin-2(1H)one (4) (Scheme 1). ${ }^{12}$ The IR spectrum of compound 4 did not revealed the $\alpha$-pyrone $(\mathrm{O}-\mathrm{C}=\mathrm{O})$ absorption band which observed at $1765 \mathrm{~cm}^{-1}$ in the IR spectrum of compound 3 . The ${ }^{1} \mathrm{H}$ NMR spectrum of compound 4 showed a characteristic singlet at $\delta 6.14 \mathrm{ppm}$ due to the active methylene protons, in addition to a broad exchangeable signal at $\delta 14.71 \mathrm{ppm}$ due to the hydroxyl proton. Formation of compound $\mathbf{4}$ takes place via the $\alpha$-pyrone ring opening with concomitant decarboxylation.

Herein, we studied the effect of high boiling solvents on compound $\mathbf{4}$ as previously published by K.V. $\mathrm{Rao}^{13}$ on 


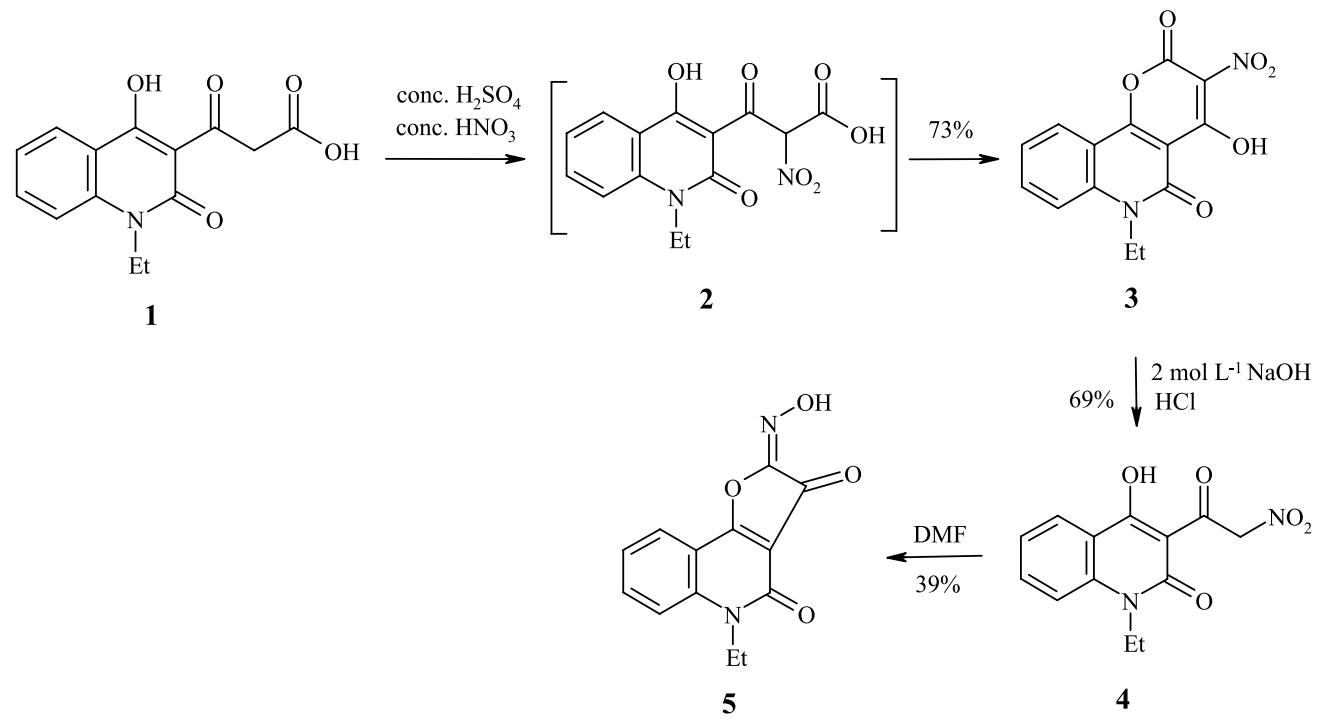

Scheme 1. Formation of 3-nitroacetylquinolinone 4 and furoquinolinone 5.

2'-nitro-2-hydroxyacetophenone. Thus, refluxing 3-nitroacetylquinolinone 4 in DMF gave 5-ethyl-2(hydroxyimino)furo[3,2-c]quinoline-3,4(2H,5H)-dione (5) (Scheme 1). The ${ }^{1} \mathrm{H}$ NMR spectrum of compound $\mathbf{5}$ reveal the disappearance of the active methylene protons which appeared at $\delta 6.14 \mathrm{ppm}$ in the ${ }^{1} \mathrm{H}$ NMR spectrum of compound 4 . The proposed mechanism of dehydration of 3-nitroacetylquinolinone 4 to produce furo[3,2-c] quinoline $\mathbf{5}$ is depicted in Scheme 2.

3-Nitroacetylquinolinone 4 was reacted with some electrophilic and nucleophilic reagents to obtain some new quinolin-2 $(1 H)$-one derivatives. Thus, bromination of compound $\mathbf{4}$ using bromine in acetic acid gave the dibromo derivative, 3-[dibromo(nitro)acetyl]-1-ethyl-4hydroxyquinolin-2(1H)-one (6). Herein, the monobromo quinolinone derivative 7 was excluded on the basis of the
${ }^{1} \mathrm{H}$ NMR spectrum which confirms the disappearance of the two active methylene protons (Scheme 3).

Also, chlorination of compound $\mathbf{4}$ using sulfuryl chloride in dioxane afforded the 3-[dichloro(nitro)acetyl]1-ethyl-4-hydroxyquinolin-2(1H)-one (8) (Scheme 3). The ${ }^{1} \mathrm{H}$ NMR spectrum of compound $\mathbf{8}$ showed signals attributed to the ethyl and aromatic protons.

We also aimed to synthesize some new $\gamma$-pyrone rings fused with the quinolin-2(1H)-one moiety to produce the pyrano[3,2-c]quinoline-4,5(6H)-diones which are rarely known in literature. ${ }^{14-16}$ Therefore, formylation of compound 4 under Vilsmeier-Haack conditions (DMF/ $\mathrm{POCl}_{3}$ ) resulted in introducing the formyl group at the active methylene carbon giving 3-(1-ethyl-4-hydroxy-2oxo-1,2-dihydroquinolin-3-yl)-2-nitro-3-oxopropanal (9) (Scheme 4). The IR spectrum of compound 9 showed a

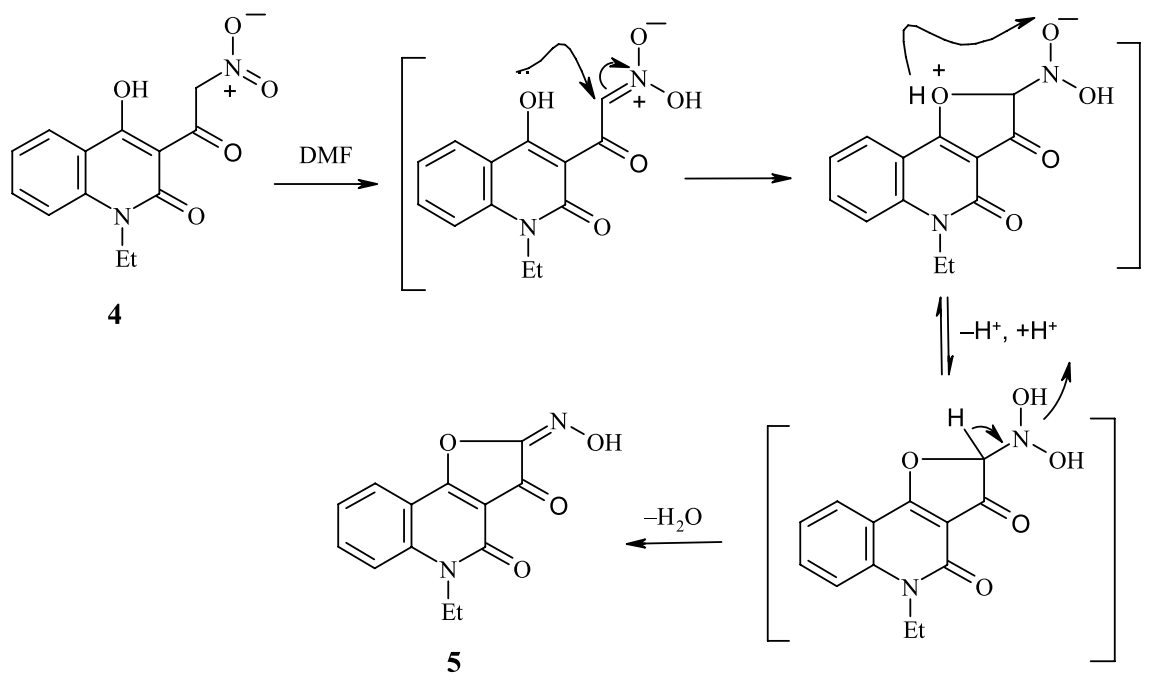

Scheme 2. The suggested mechanism for dehydration of compound 4 . 


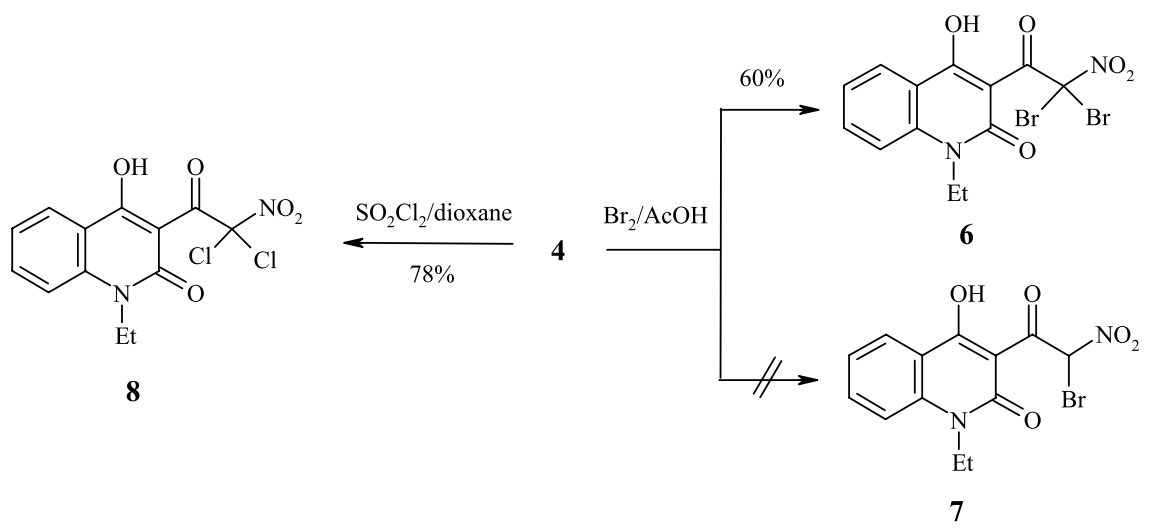

Scheme 3. Bromination and chlorination of 3-nitroacetylquinolinone 4.

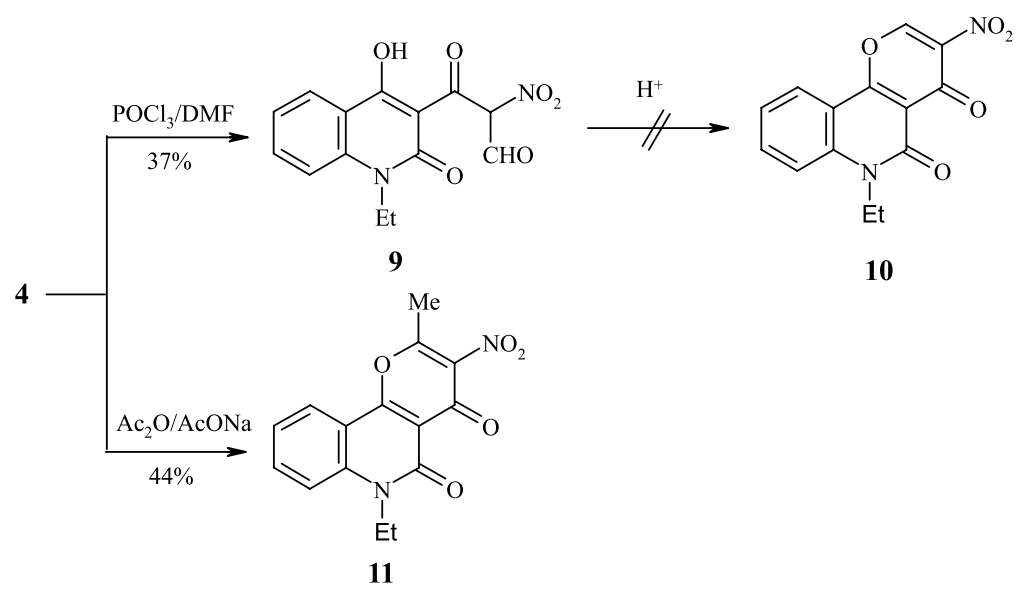

Scheme 4. Formylation and acetylation of 3-nitroacetylquinolinone 4.

characteristic absorption band at $1735 \mathrm{~cm}^{-1}$ which might be attributed to the $\mathrm{C}=\mathrm{O}$ of the aldehydic function. The ${ }^{1} \mathrm{H}$ NMR spectrum showed two characteristic singlet signals at $\delta 6.90$ and $10.29 \mathrm{ppm}$ due the $\mathrm{CHNO}_{2}$ and $\mathrm{CHO}$ protons, respectively. Further, the mass spectrum of compound 9 revealed the molecular ion peak at $\mathrm{m} / z 304$ which resembles the formula weight (304.22). Trials to cyclise compound 9 to form compound $\mathbf{1 0}$ under different acidic conditions $\left(\mathrm{EtOH} / \mathrm{HCl}\right.$, gl. $\mathrm{AcOH}$, or conc. $\mathrm{H}_{2} \mathrm{SO}_{4}$ ) failed and compound $\mathbf{9}$ was recovered.

Also, acetylation of 3-nitroacetylquinolinone 4, using acetic anhydride in the presence of freshly fused sodium acetate, led to the formation of 6-ethyl-2methyl-3-nitropyrano[3,2-c] quinoline-4,5(6H)-dione (11) (Scheme 5). ${ }^{17,18}$ The proposed mechanism for the formation of compound $\mathbf{1 1}$ is depicted in that Scheme.

The condensation reaction of 3-nitroacetylquinolinone 4 with 2-amino-3-formylchromone (12) was studied under various reaction conditions. ${ }^{19}$ Thus, condensation of $\mathbf{4}$ with 2-amino-3-formylchromone (12), in glacial acetic acid containing freshly fused sodium acetate, afforded the Knoevenagel condensation product identified as 3-[3-(2-amino-4-oxo-4H-chromen-3-yl)-2-nitroprop-2-
enoyl]-1-ethyl-4-hydroxyquinolin-2(1H)-one (13). When the latter reaction takes place in boiling DMF containing few drops of 1,8-diazabicyclo[5.4.0]undec-7-ene (DBU) as a basic catalyst afforded the Friedländer condensation product identified as 2-(1-ethyl-4-hydroxy-2-oxo-1,2dihydroquinolin-3-y)-3-nitro-5H-benzopyrano[2,3- $b$ ] pyridin-5-one (14) (Scheme 6). ${ }^{20,21}$ Compound $\mathbf{1 4}$ was obtained authentically by dehydration of compound 13 by stirring in concentrated sulfuric acid (the same $\mathrm{mp}, \mathrm{mmp}$ and spectral data were observed) (Scheme 6). The ${ }^{1} \mathrm{H}$ NMR spectrum of compound $\mathbf{1 3}$ showed a characteristic singlet at $\delta 5.46 \mathrm{ppm}$ attributed to the methine proton, while the cyclized product $\mathbf{1 4}$ showed a characteristic singlet at $\delta 8.69 \mathrm{ppm}$ assigned to the $\mathrm{H}-4$ of the pyridine ring. Also, the ${ }^{1} \mathrm{H}$ NMR spectrum of compound $\mathbf{1 4}$ reveal the disappearance of the $\mathrm{NH}_{2}$ proton signals which appeared in the ${ }^{1} \mathrm{H}$ NMR spectrum of compound $\mathbf{1 3}$ at $\delta 9.57$ and $10.04 \mathrm{ppm}$. Moreover, the IR spectrum of compound $\mathbf{1 4}$ did not revealed the absorption bands which appeared at $3298,3152 \mathrm{~cm}^{-1}$ (assigned to $\mathrm{NH}_{2}$ vibrational frequencies) in the IR spectrum of compound $\mathbf{1 3}$.

According to our previous report, ${ }^{21}$ chromone-3carbonitrile (15) was found to be chemically equivalent 
<smiles>CCn1c(=O)c(C(=O)C[N+](=O)[O-])c(O)c2ccccc21</smiles>

4

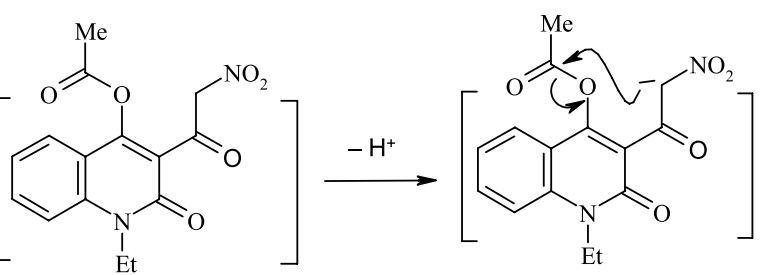

A
B<smiles>CCn1c(=O)c2c(=O)c(CO)c(C)oc2c2ccccc21</smiles>

11<smiles>CCn1c(=O)c2c(c3ccccc31)OC(C)(O)C([AlH2])C2=O</smiles>

D<smiles>CCOc1c(C(=O)C(C(C)=O)[N+](=O)[O-])c(=O)n(CC)c2ccccc12</smiles>

C

Scheme 5. The proposed mechanism for the formation of compound $\mathbf{1 1}$.

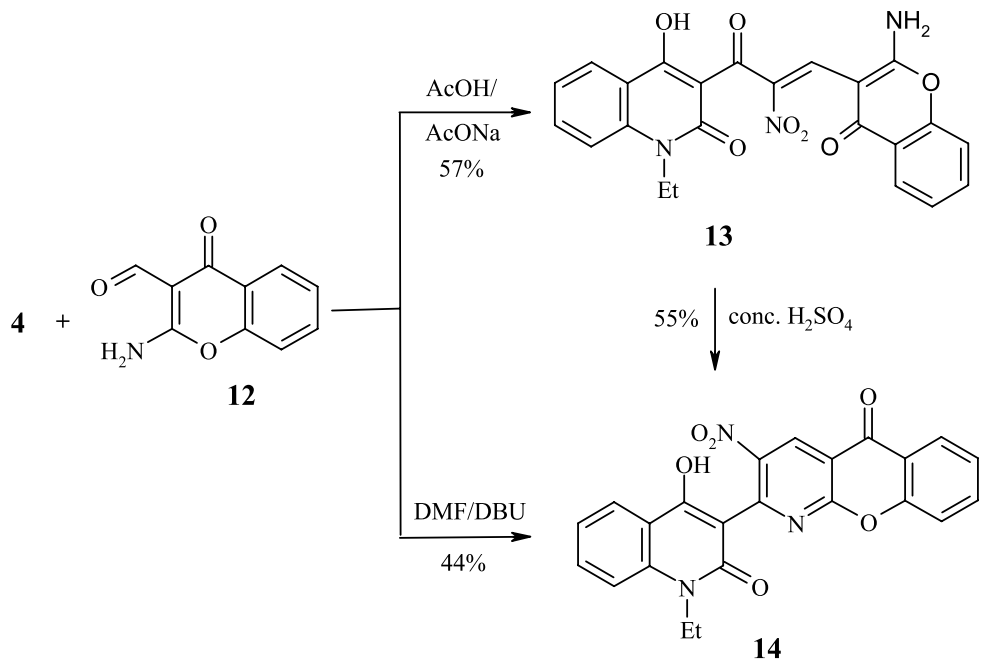

Scheme 6. Condensation of 4 with 2-amino-3-formylchromone (12).

to 2-amino-3-formylchromone under certain nucleophilic conditions. Herein again, we found that treating 3-nitroacetylquinolinone $\mathbf{4}$ with chromone-3carbonitrile $(\mathbf{1 5})^{19}$ in boiling DMF containing few drops of DBU afforded benzopyrano[2,3- $b$ ]pyridine derivative 14. Formation of compound $\mathbf{1 4}$ from carbonitrile $\mathbf{1 5}$ was accomplished via a tandem cyclization reaction through Michael addition of the active methylene group in compound $\mathbf{4}$ to the $\gamma$-pyrone moiety of carbonitrile $\mathbf{1 5}$ producing intermediate A (non-isolable). The base-mediated retroMichael analogous reaction of $\mathbf{A}$ gave the open chain intermediate $\mathbf{B}$ (non-isolable), the addition of hydroxyl group onto the nitrile function with concomitant cyclocondensation gave intermediate $\mathbf{C}$ (non-isolable) which underwent dehydration under the reaction conditions leading to the novel quinolinone bearing benzopyrano[3,2-b]pyridine $\mathbf{1 4}$. The transformation of $\mathbf{4}$ into $\mathbf{1 4}$ can be regarded as a domino "Michael/retro-Michael/nitrile-addition/ cyclocondensation" as shown in Scheme 7.22

The combination of the pyrazole or the pyrimidine nucleus with the quinoline moiety, in one molecular framework, is reported in the literature to possess biological activity. ${ }^{23-25}$ Herein, the nitroacetyl derivative $\mathbf{4}$ was allowed to react with some nucleophilic reagents. 
<smiles>CCn1c(=O)c(C(=O)C[N+](=O)[O-])c(O)c2ccccc21</smiles><smiles>CCn1c(=O)c(C(=O)CCCc2oc3ccccc3c(=O)c2C)c(C)c2ccccc21</smiles>

4 Michael-addition<smiles>CCn1c(=O)c(C(=O)C(/C=C(\C#N)C(=O)c2ccccc2O)C(=O)c2ccccc2)c(O)c2ccccc21</smiles>

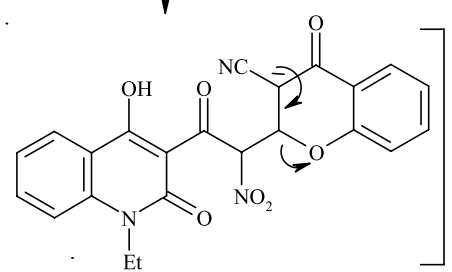

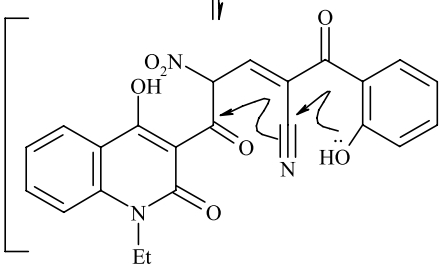
$\underset{\text { ii) Cyclocondensation }}{\stackrel{\text { Nitrile addition }}{\longrightarrow}}$<smiles>CCn1c(O)c2c(=O)c3ccccc3oc2c(C(C)(O)C(C)(C)C)c1=O</smiles><smiles>CCn1c(=O)c(-c2nc3oc4ccccc4c(=O)c3cc2[NH+]([O-])O)c(O)c2ccccc21</smiles>

Scheme 7. Reactions of compound 4 with chromone-3-carbonitrile 15.

Therefore, condensation of $\mathbf{4}$ with phenyl hydrazine and 7-chloro-4-hydrazinoquinoline (16), in glacial acetic acid containing freshly fused sodium acetate, afforded 5-ethyl3-(nitromethyl)-1-phenyl-1,5-dihydro-4H-pyrazolo[4,3-c] quinolin-4-one (17) and 1-(7-chloroquinolin-4-yl)-5-ethyl3-(nitromethyl)-1,5-dihydro-4H-pyrazolo[4,3-c] quinolin4-one (18), respectively (Scheme 8).

Recently, ${ }^{26}$ it was reported that pyrimido[5,4-c]quinolin$5(1 H)$-ones showed antioxidant and toxicological activities. For this reason and because of the well known biological activity of these ring systems, the nitroacetylquinoline $\mathbf{4}$ was employed as promising building block for the synthesis of this category of fused quinolinones. Thus, condensation of $\mathbf{4}$ with thiourea and cyanoguanidine in ethanolic potassium hydroxide solution led to 6-ethyl4-(nitromethyl)-2-thioxo-2,6-dihydropyrimido[5,4-c] quinolin-5(1H)-one (19) and [6-ethyl-4-(nitromethyl)-5oxo-5,6-dihydropyrimido[5,4-c]quinolin-2-yl]cyanamide (20), respectively (Scheme 9). The mass spectrum of compound 19 revealed the molecular ion peak at $\mathrm{m} / \mathrm{z} 316$ which resembles the formula weight (316.34).<smiles>CCn1c(=O)c2c(c3ccccc31)c1c(c(C[N+](=O)[O-])nn1-c1ccnc3cc(Cl)ccc13)c(=O)n2CC</smiles>

Scheme 8. Formation of pyrazolo[4,3-c]quinolinones $\mathbf{1 7}$ and $\mathbf{1 8 .}$

Finally, condensation of $\mathbf{4}$ with $o$-phenylenediamine in ethanol containing few drops of TEA gave 5,13-dihydro5-ethy1-7-nitromethyl-6H-quinolino[4,3-b][1,5] benzodiazepin-6-one (21) (Scheme 10). The ${ }^{1} \mathrm{H}$ NMR spectrum of compound $\mathbf{2 1}$ showed a characteristic singlet 
<smiles>CCn1c(=O)c2c(C[N+](=O)[O-])nc(=S)[nH]c2c2ccccc21</smiles>

Scheme 9. Formation of pyrimido[5,4-c]quinolinones $\mathbf{1 9}$ and 20.
4<smiles>Nc1ccccc1N</smiles>

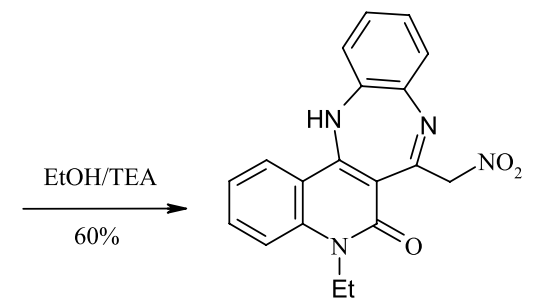

21
Scheme 10. Formation of quinolino[4,3-b][1,5]benzodiazepine 21.

at $\delta 4.93$ ppm due the $\mathrm{CH}_{2} \mathrm{NO}_{2}$ protons, in addition to eight aromatic protons and ethyl protons.

\section{Experimental}

Melting points were determined on a digital Stuart SMP3 apparatus. Infrared spectra were measured on Perkin-Elmer 293 spectrophotometer $\left(\mathrm{cm}^{-1}\right)$, using $\mathrm{KBr}$ disks. ${ }^{1} \mathrm{H}$ NMR spectra were measured on a Mercury-300BB (300 MHz), and Jeol Eca-500 MHz using DMSO- $d_{6}$ as a solvent and TMS $(\delta)$ as the internal standard. Mass spectra were obtained using a GC-2010 Shimadzu Gas chromatography instrument mass spectrometer $(70 \mathrm{eV})$. Elemental microanalyses were performed on a Perkin-Elmer CHN-2400 analyzer.

3-(1-Ethy1-4-hydroxy-2-oxo-1,2-dihydroquinolin-3-yl)-3oxopropanoic acid (1)

This compound was prepared according to our published method. ${ }^{11}$

\section{6-Ethyl-4-hydroxy-3-nitropyrano[3,2-c]quinoline-2,5(6H)} dione (3)

A mixture of $\beta$-ketoacid $1(0.55 \mathrm{~g}, 2 \mathrm{mmol})$ in concentrated nitric acid $(5 \mathrm{~mL})$ and concentrated sulfuric acid $(5 \mathrm{~mL})$ was stirred at room temperature for $2 \mathrm{~h}$, then left overnight and poured onto ice/water. The solid obtained was filtered off, washed with water and crystallized from DMF/ $\mathrm{MeOH}$ to give 3 as yellow crystals, yield $0.44 \mathrm{~g}$ (73\%).

1-Ethyl-4-hydroxy-3-(nitroacetyl)quinolin-2(1H)-one (4)

Compound 3 (0.91 g, $3 \mathrm{mmol}$ ) was dissolve in $2 \mathrm{~mol} \mathrm{~L}^{-1}$ aqueous sodium hydroxide solution $(50 \mathrm{~mL})$ and heated under reflux for $3 \mathrm{~h}$. The solution so obtained after cooling was acidified with conc. hydrochloric acid. The precipitate so formed was filtered off, washed with water, air dried and crystallized from $\mathrm{AcOH} / \mathrm{H}_{2} \mathrm{O}$ to give $\mathbf{4}$ as white crystals, yield $0.57 \mathrm{~g}(69 \%)$.

5-Ethyl-2-(hydroxyimino)-2,3,4,5-tetrahydrofuro[3,2-c] quinoline-3,4-dione (5)

Compound 4 (0.55 g, $2 \mathrm{mmol}$ ) was dissolved in DMF $(10 \mathrm{~mL})$ and heated under reflux for $4 \mathrm{~h}$. After cooling to room temperature, the reaction mixture was poured onto ice/water. The precipitate so formed was filtered off, washed with water, air dried and crystallized from DMF/EtOH to give $\mathbf{5}$ as yellow crystals, yield $0.20 \mathrm{~g}(39 \%)$.

3-[Dibromo(nitro)acetyl]-1-ethyl-4-hydroxyquinolin-2(1H)one (6)

A solution of bromine $(0.2 \mathrm{~mL}, 2 \mathrm{mmol})$ in acetic acid $(10 \mathrm{~mL})$ was added dropwise to a solution of 3-nitroacetylquinoline $4(0.55 \mathrm{~g}, 2 \mathrm{mmol})$ in acetic acid $(10 \mathrm{~mL})$. The reaction mixture was heated under reflux for $2 \mathrm{~h}$. The yellow crystals obtained after cooling were filtered off and recrystallized from $\mathrm{AcOH}$ to give $\mathbf{6}$ as yellow crystals, yield $0.52 \mathrm{~g}(60 \%)$.

3-[Dichloro(nitro)acetyl]-1-ethyl-4-hydroxyquinolin-2(1H)one (8)

To a suspension of compound $4(0.55 \mathrm{~g}, 2 \mathrm{mmol})$ in 1,4-dioxane ( $20 \mathrm{~mL})$, sulfuryl chloride ( $2 \mathrm{mmol}$ ) was added portionwise, while the temperature was not allowed to rise above $40{ }^{\circ} \mathrm{C}$. Then, the reaction mixture was stirred for 1 $\mathrm{h}$ at room temperature and poured onto ice- $\mathrm{H}_{2} \mathrm{O}(200 \mathrm{~mL})$. The formed precipitate was collected by filtration and crystallized from ethanol to give compound $\mathbf{8}$ as yellow crystals, yield $0.54 \mathrm{~g}(78 \%)$.

3-(1-Ethyl-4-hydroxy-2-oxo-1,2-dihydroquinolin-3-yl)-2nitro-3-oxopropanal (9)

Phosphoryl chloride $(3 \mathrm{~mL}$ ) was added dropwise with continuous stirring to the pre-cooled dimethylformamide $(10 \mathrm{~mL})$ in an ice bath. After complete addition, the mixture was further stirred for $30 \mathrm{~min}$ at ambient temperature, then 3-nitroacetyl derivative $4(1.10 \mathrm{~g}, 4 \mathrm{mmol})$ in dimethylformamide $(10 \mathrm{~mL})$ was added dropwise with 
continuous stirring at ambient temperature. After complete addition, the reaction mixture was heated on a boiling water bath under reflux for $2 \mathrm{~h}$ and left over night. The reddish orange solution was poured onto crushed ice and the precipitate so formed was filtered off, washed several times with water, air dried and crystallized from ethanol to give 9 as white crystals, yield $0.45 \mathrm{~g}$ (37\%).

6-Ethyl-2-methyl-3-nitro-4H-pyrano[3,2-c]quinoline-4,5(6H)dione (11)

3-Nitroacetylquinolinone $4(0.83 \mathrm{~g}, 3 \mathrm{mmol})$ in acetic anhydride $(10 \mathrm{~mL})$ and freshly fused sodium acetate was heated under reflux for $4 \mathrm{~h}$. After cooling, the reaction mixture was poured onto ice/water. The solid obtained was filtered off, washed several times with water, air dried and crystallized from ethanol to give $\mathbf{1 1}$ as pale yellow crystals, yield $0.40 \mathrm{~g}(44 \%)$.

3-[3-(2-Amino-4-oxo-4H-[1]benzopyran-3-yl)-2-nitroprop-2enoyl]-1-ethyl-4-hydroxyquinolin-2(1H)-one (13)

A mixture of compound $4(0.55 \mathrm{~g}, 2 \mathrm{mmol})$ and 2-amino3-formylchromone (12) (0.38 g, $2 \mathrm{mmol})$, in glacial acetic acid $(10 \mathrm{~mL})$ and freshly fused sodium acetate $(0.2 \mathrm{~g})$, was heated under reflux for $4 \mathrm{~h}$. The yellow crystals obtained after cooling were filtered off and recrystallized from acetic acid to give $\mathbf{1 3}$ as yellow crystals, yield $(0.51 \mathrm{~g}, 57 \%)$.

2-(1-Ethyl-4-hydroxy-2-oxo-1,2-dihydroquinolin-3-yl)-3nitro-5H-benzopyrano[2,3-b]pyridin-5-one (14)

\section{Method A}

A mixture of compound $4(0.55 \mathrm{~g}, 2 \mathrm{mmol})$ and 2-amino-3-formylchromone (12) (0.38 g, $2 \mathrm{mmol})$ or chromone-3-carbonitrile (15) (0.34 g, $2 \mathrm{mmol})$, in DMF $(10 \mathrm{~mL})$ containing few drops of DBU, was heated under reflux for $3 \mathrm{~h}$. The yellow crystals obtained after cooling were filtered off and recrystallized from DMF/EtOH to give $\mathbf{1 4}$ as yellow crystals, yield $44-48 \%$.

\section{Method B}

Compound 13 (0.45 g, $1 \mathrm{mmol})$ in concentrated $\mathrm{H}_{2} \mathrm{SO}_{4}$ $(5 \mathrm{~mL})$ was stirred at room temperature for $1 \mathrm{~h}$. The dark brown solution was poured onto ice/water, the precipitate so formed was filtered off, washed several times with water and crystallized from $\mathrm{DMF} / \mathrm{EtOH}$ to give $\mathbf{1 4}$ as yellow crystals, yield $0.24 \mathrm{~g}(55 \%)$.

5-Ethyl-3-(nitromethyl)-1-phenyl-1,5-dihydro-4 Hpyrazolo[4,3-c]quinolin-4-one (17)

A mixture of compound $4(0.55 \mathrm{~g}, 2 \mathrm{mmol})$ and phenyl hydrazine $(0.2 \mathrm{~mL}, 2 \mathrm{mmol})$, in glacial acetic acid $(15 \mathrm{~mL})$ and freshly fused sodium acetate $(0.2 \mathrm{~g})$, was heated under reflux for $4 \mathrm{~h}$. The yellow crystals obtained after cooling were filtered off and recrystallized from $n$-butanol to give 17 as yellow crystals, yield $0.48 \mathrm{~g}(73 \%)$.

1-(7-Chloroquinolin-4-yl)-5-ethyl-3-(nitromethyl)-1,5dihydro-4H-pyrazolo[4,3-c]quinolin-4-one (18)

A mixture of compound 4 ( $0.55 \mathrm{~g}, 2 \mathrm{mmol})$, 7-chloro-4hydrazinoquinoline (16) $(0.36 \mathrm{~g}, 2 \mathrm{mmol})$, in glacial acetic acid $(15 \mathrm{~mL})$ and freshly fused sodium acetate $(0.2 \mathrm{~g})$, was heated under reflux for $4 \mathrm{~h}$. The yellow crystals obtained after cooling were filtered off and recrystallized from DMF/ EtOH to give 18 as yellow crystals, yield $0.42 \mathrm{~g}(64 \%)$.

6-Ethyl-4-(nitromethyl)-2-thioxo-1,2,5,6-tetrahydropyrimido[5,4-c]quinolin-5(1H)-one (19)

A mixture of 3-nitroacetylquinoline 4 ( $0.55 \mathrm{~g}, 2 \mathrm{mmol})$ and thiourea $(0.15 \mathrm{~g}, 2 \mathrm{mmol})$ in ethanolic potassium hydroxide solution (15 mL, 10\%) was heated under reflux for $4 \mathrm{~h}$. After cooling at room temperature, the reaction mixture was poured onto crushed ice and neutralized with concentrated $\mathrm{HCl}$. The precipitate so formed was filtered off, washed with water and crystallized from acetic acid/water to afford $\mathbf{1 9}$ as yellow crystals, yield $0.38 \mathrm{~g}$ $(61 \%)$.

[6-Ethyl-4-(nitromethyl)-5-oxo-5,6-dihydropyrimido[5,4-c] quinolin-2(1H)-yl]cyanamide (20)

A mixture of 3-nitroacetylquinoline 4 ( $0.55 \mathrm{~g}, 2 \mathrm{mmol})$ and cyanoguanidine $(0.17 \mathrm{~g}, 2 \mathrm{mmol})$ in ethanolic potassium hydroxide solution $(15 \mathrm{~mL}, 10 \%)$ was heated under reflux for $4 \mathrm{~h}$. After cooling at room temperature, the reaction mixture was poured onto crushed ice and neutralized with concentrated $\mathrm{HCl}$. The precipitate so formed was filtered off, washed with water and crystallized from ethanol to afford 20 as yellow crystals, yield $0.37 \mathrm{~g}$ (57\%).

5,13-Dihydro-5-ethyl-7-nitromethyl-6H-quinolino[4,3-b][1,5] benzodiazepin-6-one (21)

A mixture of 3-nitroacetylquinoline 4 ( $0.55 \mathrm{~g}, 2 \mathrm{mmol})$ and $o$-phenylenediamine $(0.22 \mathrm{~g}, 2 \mathrm{mmol})$, in ethanol containing few drops of triethylamine, was heated under reflux for $3 \mathrm{~h}$. The solid obtained during heating was filtered off and crystallized from ethanol to afford $\mathbf{2 1}$ as yellow crystals, yield $0.42 \mathrm{~g}(60 \%)$.

\section{Supplementary Information}

Data spectra and spectra of synthesized compounds are available free of charge at http://jbcs.sbq.org.br as PDF file. 


\section{References}

1. Hayashi, H.; Miwa, I.; Ichikawa, S.; Yoda, N.; Miki, I.; Ishii, A.; Kono, M.; Yasuzawa, T.; Suzuki, F.; J. Med. Chem. 1993, 36, 617.

2. Cheng, P.; Gu, Q.; Liu, W.; Zou, J.-F.; Ou, Y.- Y.; Luo, Z.-Y.; Zeng, J.-G.; Molecules 2011, 16, 7649.

3. De Vita, R. J.; Hollings, D. D.; Goulet, M. T.; Wyvratt, M. J.; Fischer, M. H.; Lo, J. L.; Yang, Y. T.; Cheng, K.; Smith, R. G.; Bioorg. Med. Chem. Lett. 1999, 9, 2615.

4. Kreimeyer,A.; Laube, B.; Sturgess, M.; Goeldner, M.; Foucaud,B.; J. Med. Chem. 1999, 42, 4394.

5. Chen, I-L.; Chang, K.-M.; Miaw, C.-L.; Liao, C.-H.; Chen, J.-J.; Wang, T.-C.; Bioorg. Med. Chem. 2007, 15, 6527.

6. de Melo, E. B.; Eur. J. Med. Chem. 2010, 45, 5817.

7. Taylor, J. G.; Correia, C. R. D.; J. Org. Chem. 2011, 76, 857.

8. Abass, M.; Ismail, M. M.; Chem. Pap. 2000, 54, 187.

9. Siddiqui, I. R.; Shamim, S.; Singh, A.; Srivastava, V.; Yadav, S.; ARKIVOC 2010, xi, 232.

10. Gao, W.-T.; Hou, W.-D.; Zheng, M.-R.; Tang, L.-J.; Synth. Commun. 2010, 40, 732.

11. Ibrahim, M. A.; Hassanin, H. M.; Gabr, Y. A.; Alnamer, Y. A.; Eur. J. Chem. 2010, 1, 195.

12. El-Taweel, F. M. A.; Ibrahim, D. A.; Hanna, M. A.; Boll. Chim. Farm. 2001, 140, 287.

13. Rao, K. V.; Ind. Eng. Chem. Res. 2002, 41, 3333.
14. Abdel-Megid, M.; Abass, M.; Hassan, M.; J. Heterocycl. Chem. 2007, 44, 315.

15. Ismail, M. M.; Mohamed, H. M.; Chem. Pap. 2005, 59, 127.

16. Ibrahim, S. S.; Abdel-halim, A. M.; Ismail, M. M.; Othman, E. S.; Indian J. Heterocycl. Chem. 1994, 4, 125.

17. Lacova, M.; El-Shaaer, H. M.; Matulova, M.; Chovacoua, J.; Furdik, M.; Molecules 1998, 3, 120.

18. Ghosh, C. K.; Bhattacharyya, S.; Ghosh, C.; Patra, A.; J. Chem. Soc., Perkin Trans1 1999, 1, 3005.

19. Petersen, U.; Heitzer, H.; Liebigs Ann. Chem. 1976, 9, 1659.

20. Ibrahim, M. A.; Eur. J. Chem. 2010, 14, 124.

21. Ibrahim, M. A.; Synth. Commun. 2009, 39, 3527.

22. Rashid, M. A.; Rasool, N.; Appel, B.; Adeel, M.; Karapetyan, V.; Mkrtchyan, S.; Reinke, H.; Fischer, C.; Langer, P.; Tetrahedron 2008, 64, 5416.

23. López Rivilli, M. J.; Moyano, E. L.; Yranzo, G. I.; Tetrahedron Lett. 2010, 51, 478.

24. Christodoulou, M. S.; Liekens, S.; Kasiotis, K. M.; Haroutounian, S. A.; Bioorg. Med. Chem. 2010, 18, 4338.

25. Pawlas, J.; Vedso, P.; Jakobsen, P.; Huusfeldt, P. O.; Begtrup, M.; J. Org. Chem. 2000, 65, 9001.

26. Sankaran, M.; Kumarasamy, C.; Chokkalingam, U.; Mohan, P. S.; Bioorg. Med. Chem. Lett. 2010, 20, 7147.

Submitted: November 9, 2011 Published online: April 17, 2012 